IZA DP No. 7391

Disease and Development Revisited

David E. Bloom

David Canning

Günther Fink

May 2013 


\title{
Disease and Development Revisited
}

\author{
David E. Bloom \\ Harvard School of Public Health \\ and IZA \\ David Canning \\ Harvard School of Public Health \\ Günther Fink \\ Harvard School of Public Health
}
Discussion Paper No. 7391
May 2013

IZA

P.O. Box 7240

53072 Bonn

Germany

Phone: +49-228-3894-0

Fax: +49-228-3894-180

E-mail: iza@iza.org

Any opinions expressed here are those of the author(s) and not those of IZA. Research published in this series may include views on policy, but the institute itself takes no institutional policy positions. The IZA research network is committed to the IZA Guiding Principles of Research Integrity.

The Institute for the Study of Labor (IZA) in Bonn is a local and virtual international research center and a place of communication between science, politics and business. IZA is an independent nonprofit organization supported by Deutsche Post Foundation. The center is associated with the University of Bonn and offers a stimulating research environment through its international network, workshops and conferences, data service, project support, research visits and doctoral program. IZA engages in (i) original and internationally competitive research in all fields of labor economics, (ii) development of policy concepts, and (iii) dissemination of research results and concepts to the interested public.

IZA Discussion Papers often represent preliminary work and are circulated to encourage discussion. Citation of such a paper should account for its provisional character. A revised version may be available directly from the author. 


\section{ABSTRACT}

\section{Disease and Development Revisited ${ }^{1}$}

Acemoglu and Johnson (2007) present evidence that improvements in population health do not promote economic growth. We show that their result depends critically on the assumption that initial health has no causal effect on subsequent economic growth. We argue that such an effect is likely, primarily because childhood health affects adult productivity. In our augmented model, which includes initial health, the instrumental variable proposed by Acemoglu and Johnson has no significant predictive power for improvements in health and does not identify the effect of contemporaneous improvements in health on economic growth.

JEL Classification: $\quad$ I10, O40

Keywords: health, development, economic growth

Corresponding author:

David E. Bloom

Harvard School of Public Health

Department of Global Health and Population

665 Huntington Avenue

Building I 12th Floor, Suite 1202

Boston, MA 02115

USA

E-mail: dbloom@hsph.harvard.edu

\footnotetext{
${ }^{1}$ We are grateful to Daron Acemoglu and Simon Johnson for sharing their data and analysis files, as well as to four anonymous referees and the editor of this journal for helpful comments. We would also like to thank Andreas Bergh, Hoyt Bleakley, Jocelyn Finlay, Isabel Günther, Dean Jamison, Aart Kray, Sebastian Linnemayr, and seminar participants at Lund University and the Workshop on Health and Macroeconomics in Madrid for useful discussions. Support for this research was provided by the William and Flora Hewlett Foundation, as well as by grant number 5 P30 AG024409 from the National Institute on Aging, National Institutes of Health.
} 


\section{Introduction}

In a recent paper, Acemoglu and Johnson (2007) present empirical results indicating that improvements in population health may have lowered the pace of economic growth. These results contradict much of the preceding literature reviewed in Weil (2007) as well as Bloom, Canning, and Sevilla (2004), which generally finds that countries with better population health experience faster economic growth. The rationale for Acemoglu and Johnson's view is that while health improvements may increase human capital and worker productivity, lower mortality may increase population size and thereby reduce other factor inputs on a per capita basis.

Acemoglu and Johnson's main argument builds on the observation that improvements in health and economic growth are negatively correlated over the period 1940-2000. We argue that this is not because improvements in health have a deleterious effect on economic growth, but rather because countries that were healthier in 1940 experienced faster subsequent economic growth. Since countries with higher life expectancy in 1940 also experienced less rapid health gains between 1940 and 2000, we observe that health improvements and economic growth are negatively correlated over the same period.

Acemoglu and Johnson show that the negative relationship between improvements in health and economic growth persists even when they instrument health improvements. The instrument they use, mortality from a set of selected diseases in 1940, is a subset of total mortality in 1940, and thus highly correlated with initial life expectancy. In response to an earlier version of this paper (Bloom, Canning and Fink 2009), Acemoglu and Johnson acknowledge this correlation, but defend the appropriateness of excluding initial health from their economic growth specification (Acemoglu and Johnson 2009). The key issue therefore is whether it is 
plausible that initial life expectancy can be excluded from the growth regression on a priori grounds.

Conditional convergence models of economic growth (Barro and Sala-i-Martin 2004; Durlauf, Johnson and Temple 2005) are based on the idea that income adjusts slowly to its steady state, which suggests substantial lags between changes in fundamentals and economic growth. A particular justification of slow adjustment to steady state in the case of health is that health human capital is constructed in childhood and has economic benefits only when these children become adults.

Health in this cross-country study is measured by life expectancy. While life expectancy depends on age-specific mortality at all ages, the wide gaps in life expectancy in the sample are predominantly due to differences in infant and child mortality. Mortality improvements at older ages only play a major role in life expectancy increases when infant mortality is low and life expectancy is already quite high (Vaupel 1986; de Castro 2001).

Reductions in infant mortality rates are unlikely to promote worker productivity in the short run. However reductions in infant mortality are correlated with improvements in child health and physical development in the form of adult height (Crimmins and Finch 2006; Akachi and Canning 2007). Microeconomic studies suggest that early childhood health affects physical and cognitive development, educational outcomes, and productivity when the cohort reaches working age (Barker 1992; Bleakley 2003; Behrman and Rosenzweig 2004; Kremer and Miguel 2004; Case, Fertig and Paxson 2005; Heckman 2007; Hoddinott, Maluccio, Behrman, Flores et al. 2008; Bleakley 2010; Baird, Hicks, Kremer and Miguel 2011). The health human capital of current workers may therefore reflect their childhood health, as measured by infant and child 
mortality rates and life expectancy many decades prior, creating a long lag between health improvements and productivity gains.

While we think slow adjustment to steady state when health improves due to the delayed economic benefits from improvements in childhood health is plausible, any model that incorporates an effect of initial health on subsequent economic growth will have similar results to ours. For example, endogenous growth models in the tradition of Nelson and Phelps (1966), which include health human capital as a driver of technological change, will yield similar results to our model ${ }^{2}$ (Aghion, Howitt and Murtin 2011).

If initial life expectancy matters for economic growth, and the Acemoglu and Johnson instrument is correlated with this omitted variable, their estimates are likely to be inconsistent. Assuming the response of income to life expectancy follows a partial adjustment process, we show that both levels and improvements in life expectancy have a significant and positive effect on economic growth in a simple OLS framework. Once we control for initial life expectancy, the Acemoglu and Johnson instrument has almost no predictive power for improvements in life expectancy, so that it cannot be used to identify the causal effect of changes in health on economic growth.

The Acemoglu and Johnson model essentially estimates a bivariate relationship between improvements in life expectancy and economic growth. The exclusion of all other growth determinants would be reasonable if their instrument, changes in predicted mortality, had the properties of a controlled trial, randomly allocating health improvements to countries. However, their instrument is not random, but essentially a measure of national health in 1940. If initial health has a direct causal effect on economic growth as we argue above, the instrument is clearly

\footnotetext{
${ }^{2}$ Models of endogenous growth have, however, a rather different long-run implication, predicting much higher rates of divergence in long-term growth than historically observed.
} 
invalid. Even if initial health does not have a causal effect on economic growth, but is correlated with any actual determinant of economic growth, the instrument will in all likelihood also be correlated with that growth determinant, so the resulting instrumental variable estimates will be inconsistent.

Acemoglu and Johnson report an extensive set of robustness checks to defend the validity of their instrument. They go to great lengths to demonstrate that the instrument is predictive of improvements in life expectancy post-1940, while it is not predictive of changes in health or income between 1900 and 1940. Even though these tests provide strong support for the timing and impact of the analyzed health innovations, they do not address the fundamental omitted variable concern raised in this paper. While the original Acemoglu and Johnson article does show their results are robust to including initial income and a measure of institutional quality, we show that their results are not robust to including initial life expectancy.

\section{Empirical Results}

We begin by examining the 47 data points used in Acemoglu and Johnson's main regressions. The data were provided by the authors and are as described in their original paper (Acemoglu and Johnson 2007). The key variables are log GDP per capita, log life expectancy, and predicted mortality. Predicted mortality is total number of deaths per 100 people in 1940 that are attributable to the 15 diseases that were subject to significant advances in prevention or treatment after 1940. After 1960, predicted mortality is coded as zero for all countries. The Acemoglu and Johnson instrument for the change in life expectancy between 1940 and 2000 is the change in predicted mortality over the period, which equals the negative of predicted mortality in 1940. 
Table 1 reports pairwise correlations for all key variables. The correlation between initial life expectancy and subsequent change in life expectancy is -0.97 , reflecting the strong crosscountry convergence in life expectancy over the period 1940 to 2000 (Cutler, Deaton and LlerasMuney 2006). The correlation between initial life expectancy and predicted mortality in 1940 is 0.70 (see Figure 1). Also notable are the strong and statistically significant positive correlations between the log of initial life expectancy and both the log of initial income per capita and the subsequent growth in income per capita (correlations of 0.81 and 0.5 , respectively).

The empirical model used by Acemoglu and Johnson is a basic difference-in-differences model, where the change in log GDP per capita ( $\Delta y)$ in country $i$ at time $t$ is given by

$$
\Delta y_{i t}=\alpha_{t}+\beta \Delta x_{i t}+\varepsilon_{i t},
$$

where $\Delta x$ is the change in log life expectancy, $\alpha_{t}$ is a period-specific constant, and $\varepsilon_{i t}$ is the error term. Since both life expectancy and GDP per capita are in logs, the differences $\Delta y_{i t}$ and $\Delta x_{i t}$ can be interpreted as growth rates. We follow Acemoglu and Johnson and assume a linear relation between changes in log income and changes in log life expectancy. This assumption has been challenged by Cervellati and Sunde (2011), who argue that the effects of changes in health differ across stages of the demographic transition. It is easy to see that Acemoglu and Johnson's empirical model (1) is nested in a more general conditional convergence model

$$
\Delta y_{i t}=\alpha_{t}+\beta \Delta x_{i t}+\gamma x_{i, t-1}-\lambda y_{i, t-1}+\varepsilon_{i t}
$$

under the assumption that $\gamma=\lambda=0 .^{3}$

A similar empirical specification can be derived from a model in levels $y_{i t}=\delta_{t}+\beta x_{i t}+u_{i t}$ under the assumption that rather than adjusting to equilibrium immediately, the error term $u_{i t}$

\footnotetext{
${ }^{3}$ Acemoglu and Johnson sometimes allow for a lagged income effect, but not a lagged health effect, in their robustness checks. It is the lagged health effect that is crucial to our argument.
} 
follows a first-order autoregressive (AR1) process $u_{i t}=(1-\lambda) u_{i t-1}+\varepsilon_{i t}$. The AR1 process in levels can be written in differences as:

$$
\Delta y_{i t}=\alpha_{t}+\beta \Delta x_{i t}+\lambda \beta x_{i, t-1}-\lambda y_{i, t-1}+\varepsilon_{i t}
$$

As discussed in Bloom, Canning, and Sevilla (2004), this specification is the same as the more general dynamic model given by equation (2) but imposes the common factor restriction $\gamma=\lambda \beta$. Equation (3) is an error correction model in which income adjusts slowly towards its steady-state value. The Acemoglu and Johnson specification is a special case of this model in which $\lambda=0$, which also implies that $\gamma=0$. While $\lambda$ can be expected to be small over short time intervals, our view is that over long time intervals $\lambda$ should approach unity as all of the initial disequilibrium is corrected.

Table 2 reports regression results using the 47-country Acemoglu and Johnson data set. The dependent variable in all regressions is growth in per capita income during 1940-2000. In column 1 of Table 2 we replicate the Acemoglu and Johnson results, regressing changes in income per capita on changes in log life expectancy using ordinary least squares (OLS). The point estimate of -1.14 (statistically significant at the $99 \%$ level) implies that a $10 \%$ increase in life expectancy leads to an $11.4 \%$ decrease in GDP per capita. In column 2 of Table 2, we replicate another key Acemoglu and Johnson result by instrumenting the change in log life expectancy with the predicted mortality change (this is just the negative of predicted mortality in 1940 since predicted mortality in 2000 is taken to be zero). These estimates suggest that the effect of growth in life expectancy on income growth is negative (a coefficient of -1.51) and statistically significant. 
In column 3 of Table 2, we include initial log life expectancy along with the growth rate in life expectancy as predictors of economic growth in a simple OLS regression ${ }^{4}$. This reverses the sign of the estimated coefficient on the growth in life expectancy, suggesting a positive effect of the growth in life expectancy on economic growth. However this regression may be subject to bias due to reverse causality from economic growth to the growth in life expectancy or other omitted variables. We refit this regression in column 4 of Table 2, but instrument growth in life expectancy with the predicted mortality change. None of the resulting coefficient estimates are statistically significant. While the point estimate of the effect of the growth in life expectancy is large and negative, the standard error and confidence intervals are very large, which is the result of the instrument's lack of predictive power in the first-stage regression. A Cragg-Donald FStatistic of 0.137 implies that the partial correlation between predicted mortality and subsequent changes in life expectancy is virtually zero once we control for initial life expectancy. The results of the first-stage regressions are reported in Web Appendix Table WA5.

In column 5 we add initial log income per capita to the model in order to estimate the parameters of the empirical model given by equation (2). While we find a negative coefficient between zero and unity on initial GDP - as is standard in the literature on conditional convergence - the inclusion of initial GDP increases the estimated effect of both initial health and health improvements on economic growth. We also fit this model using the change in predicted mortality as an instrument for the improvement in life expectancy. The results are reported in column 6 of Table 2. Once again, the instrument is too weak in the first stage to give precise estimates of the effect of improvements in life expectancy. Given that the instruments are weak, the conventional standard errors for the IV regressions in columns (2), (4) and (6) may be

\footnotetext{
${ }^{4}$ This is equivalent to adding initial life expectancy interacted with a year dummy as an explanatory variable in the levels equation. Acemoglu and Johnson use this interacted specification in some of their first-stage robustness checks, but not in any of their two-stage least-squares estimates.
} 
unreliable; we therefore also give $80 \%$ confidence intervals for the coefficient on the endogenous variable, the growth in life expectancy, that are robust to weak instruments (see web appendix for details). In columns (4) and (6) the instrument is so weak that these confidence intervals are unbounded.

In column 7 of Table 2 we report a reduced-form estimate of the model in column (6) in which we replace the growth in life expectancy with predicted mortality in 1940. Conditional on initial income and health, predicted mortality in 1940 has no significant effect on economic growth. Given that predicted mortality is not predictive of subsequent improvements in health conditional on initial health, this is perhaps not surprising.

All estimates reported in columns (5) through (8) of Table 2 are based on the assumption that both initial health and changes in health matter for economic growth. Given that actual and predicted changes in life expectancy may be correlated with other omitted determinants of growth even after controlling for initial health and income, our models do not conclusively demonstrate the causal effect of improvements in health on economic growth. Our results do, however, show how sensitive the Acemoglu and Johnson results are to the model specification in general, and to the inclusion of initial life expectancy in particular.

\section{Conclusion}

Acemoglu and Johnson’s (2007) results are striking because they imply that health improvements impede economic growth. This finding is at odds with most of the previous literature on economic growth. We show that the Acemoglu and Johnson result is mostly driven by their a priori exclusion of initial life expectancy from the economic growth model. While the mortality instrument constructed by Acemoglu and Johnson is predictive of improvements in 
health, it also displays a strong negative correlation with initial life expectancy and fails as an instrument if initial life expectancy is a determinant of subsequent economic growth. In a more general empirical framework in which we include initial life expectancy, the Acemoglu and Johnson results are reversed, with both levels and changes in health displaying positive associations with economic growth.

In our view, the evidence presented by Acemoglu and Johnson is compatible with a world in which good initial health is a strong driver of subsequent economic growth. As we show in the Appendix, countries with poor initial health have consistently experienced slower economic growth throughout the $20^{\text {th }}$ century. Since countries with poor initial health have also experienced the most rapid gains in health as new health technologies became available to tackle their high burden of disease, the negative correlation between gains in health and economic growth observed by Acemoglu and Johnson appears; this correlation should however not be given causal interpretations since both health improvements and slow economic growth are driven by poor initial health.

An alternative view compatible with the data is that initial health is positively correlated with some other unobserved (and excluded) growth determinant such as education or social capital. Under this scenario, the negative growth effects identified by the Acemoglu and Johnson instrument will not only represent the effect of changes in health, but also the economic consequences of lacking education or social capital. Controlling for initial health as a proxy for these omitted factors will then improve the estimates. This may explain why the estimated coefficients on health in columns 3 and 5 are large, with a one-year increase in life expectancy raising income by between 5 and 15 percent over a 60-year period. In the Web Appendix, we show that these results are also robust to the inclusion of the baseline stock of physical capital 
and investment flows as well as average years of schooling and the school enrollment rate. In previous work, Bloom, Canning, and Sevilla (2004) estimated the parameters of equation (3) for a panel of countries using a rich set of additional covariates and find a much smaller positive effect of health on economic growth, which suggests that other excluded determinants of growth are important and are correlated with health. Similarly, Lorentzen et al. (2008) estimate the effect of initial health on subsequent economic growth using a variety of instrumental variables to overcome this problem, and still find a positive impact. The ultimate goal of the present paper is not, however, to provide a comprehensive model of economic growth, but rather to highlight the sensitivity of the Acemoglu and Johnson results to the inclusion of baseline health.

While we think that the inference reported by Acemoglu and Johnson is incorrect, their paper identifies several crucial issues not yet resolved in the literature. First, Acemoglu and Johnson place appropriate stress on the fundamental endogeneity concerns surrounding the identification of health effects in macro-level regressions. Second, the Acemoglu and Johnson paper highlights the critical importance of lag structures in models of health and economic growth. Last, Acemoglu and Johnson make a strong case for the importance of population in the interplay between health and economic development. While health is likely to have positive growth repercussions due to improved productivity and human capital increases, the general equilibrium effects of health can only be understood if the population effects of changes in health as well as the resulting resource pressures are fully taken into account. 


\section{References}

Acemoglu, Daron and Simon Johnson. 2007. "Disease and Development: The effect of life expectancy on economic growth." Journal of Political Economy 115(6): 925-985.

Acemoglu, Daron and Simon Johnson. 2009. Disease and Development: A Reply to Bloom,Canning, and Fink. Manuscript, MIT.

Aghion, Philippe , Peter Howitt and Fabrice Murtin. 2011. The Relationship Between Health and Growth: When Lucas Meets Nelson-Phelps. Review of Economics and Institutions 2(1), 24 http://www.rei.unipg.it/rei/article/view/22.

Akachi, Yoko and David Canning. 2007. "The Height of Women in Sub-Saharan Africa: the Role of Health, Nutrition, and Income in Childhood." Annals of Human Biology 34(4): 397-410.

Baird, Sarah, Joan H. Hicks, Michael Kremer and Edward Miguel. 2011. Worms at work: longrun impacts of child health gains. Manuscript, University of California, Berkeley.

Barker, David J.P. 1992. The Fetal and Infant Origins of Adult Disease. London, BMJ Books.

Barro, Robert J. and Xavier Sala-i-Martin. 2004. Economic Growth. Cambridge, MA, MIT Press.

Behrman, Jere R. and Mark R. Rosenzweig. 2004. "The Returns to Birthweight." Review of Economics and Statistics 86(2): 586-601. 
Bleakley, Hoyt. 2003. "Disease and Development: Evidence from the American South." Journal of the European Economic Association 1(2-3): 376-386.

Bleakley, Hoyt. 2010. "Malaria eradication in the Americas: A retrospective analysis of childhood exposure." American Economic Journal: Applied Economics 2(2): 1-45.

Bloom, David E., David Canning and Günther Fink. 2009. Disease and Development Revisited. Working Paper 15137. Cambridge MA, NBER.

Bloom, David E., David Canning and Jaypee Sevilla. 2004. "The Effect of Health on Economic Growth: A Production Function Approach." World Development 32(1): 1-13.

Case, Anne, Angela Fertig and Christina Paxson. 2005. "The Lasting Impact of Childhood Health and Circumstance." Journal of Health Economics 24(2): 365-389.

Cervellati, Matteo and Uwe Sunde. 2011. "Life Expectancy and Economic Growth: The Role of the Demographic Transition." Journal of Economic Growth 16(2): 99-133.

Crimmins, Eileen M. and Caleb E. Finch. 2006. "Infection, inflammation, height, and longevity." Proceedings of the National Academy of Sciences 103(2): 498-503. 
Cutler, David, Angus Deaton and Adriana Lleras-Muney. 2006. "The Determinants of Mortality." Journal of Economic Perspectives 20(3): 97-120.

de Castro, Marcia C. 2001. "Changes in mortality and life expectancy: Some methodological issues." Mathematical Population Studies 9(3-4): 181-208.

Durlauf, Steven, Paul Johnson and Jonathan Temple. 2005. Growth Econometrics. Handbook of Economic Growth. P. Aghion and S. Durlauf. Amsterdam, Elsevier.

Heckman, James J. 2007. "The economics, technology, and neuroscience of human capability formation." Proceedings of the National Academy of Sciences 104(33): 13250-13255.

Hoddinott, J., J.A. Maluccio, J.R. Behrman, R. Flores and R. Martorell. 2008. "Effect of a nutrition intervention during early childhood on economic productivity in Guatemalan adults." The Lancet 371(9610): 411-416.

Kremer, Michael and Edward Miguel. 2004. "Worms: Identifying Impacts on Education and Health in the Presence of Treatment Externalities " Econometrica 72(1): 159 - 217.

Lorentzen, Peter, John McMillan and Romain Wacziarg. 2008. "Death and development." Journal of Economic Growth 13(2): 81-124. 
Nelson, R. and E. Phelps. 1966. "Investment in Humans, Technological Diffusion, and Economic Growth." American Economic Review 61: 69-75.

Vaupel, James W. 1986. "How change in age-specific mortality affects life expectancy." Population Studies 40(1): 147-157.

Weil, David. 2007. "Accounting for the Effect of Health on Economic Growth." Quarterly Journal of Economics 122(3): 1265-1306. 
TABle 1: Correlation MATrix: ACEMOglu AND Johnson SAMPle of 47 Countries

\begin{tabular}{|c|c|c|c|c|c|c|}
\hline & $\begin{array}{c}\text { Growth in } \\
\text { income per capita } \\
1940-2000 \\
\end{array}$ & $\begin{array}{c}\text { Growth in life } \\
\text { expectancy } \\
1940-2000 \\
\end{array}$ & $\begin{array}{c}\text { Change in } \\
\text { predicted mortality } \\
1940-2000\end{array}$ & $\begin{array}{c}\text { Log life } \\
\text { expectancy } 1940\end{array}$ & $\begin{array}{c}\text { Log GDP per } \\
\text { capita } 1940\end{array}$ & $\begin{array}{c}\text { Predicted } \\
\text { mortality } 1940\end{array}$ \\
\hline Growth in income per capita 1940-2000 & 1 & & & & & \\
\hline Growth in life expectancy 1940-2000 & $-0.44 * * *$ & 1 & & & & \\
\hline $\begin{array}{l}\text { Change in predicted mortality } 1940- \\
2000\end{array}$ & $0.34^{* *}$ & $-0.69 * * *$ & 1 & & & \\
\hline Log life expectancy 1940 & $0.50 * * *$ & $-0.97 * * *$ & $0.70^{* * *}$ & 1 & & \\
\hline Log GDP per capita 1940 & 0.13 & $-0.76 * * *$ & $0.63 * * *$ & $0.81 * * *$ & 1 & \\
\hline Predicted mortality 1940 & $-0.34 * *$ & $0.69 * * *$ & -1 & $-0.70 * * *$ & $-0.63 * * *$ & 1 \\
\hline
\end{tabular}


TABLE 2: GROWTH REGRESSIONS

\section{DEPENDENT VARIABLE： GROWTH IN INCOME PER CAPITA, 1940-2000}

\begin{tabular}{|c|c|c|c|c|c|c|c|}
\hline \multirow[t]{2}{*}{ Specification } & \multicolumn{2}{|c|}{ Acemoglu \& Johnson } & \multicolumn{2}{|c|}{ Adding initial health } & \multicolumn{2}{|c|}{$\begin{array}{l}\text { Adding initial health and } \\
\text { income }\end{array}$} & \multirow{2}{*}{$\begin{array}{c}\text { Reduced } \\
\text { Form } \\
(7)\end{array}$} \\
\hline & (1) & $(2)$ & (3) & (4) & (5) & (6) & \\
\hline Estimator & $\begin{array}{l}\text { Least } \\
\text { Squares }\end{array}$ & IV & $\begin{array}{l}\text { Least } \\
\text { Squares }\end{array}$ & IV & $\begin{array}{l}\text { Least } \\
\text { Squares }\end{array}$ & IV & $\begin{array}{l}\text { Least } \\
\text { Squares }\end{array}$ \\
\hline $\begin{array}{r}\text { Growth in life expectancy 1940-2000 } \\
\text { (Standard error) }\end{array}$ & $\begin{array}{c}-1.142 * * * \\
(0.347)\end{array}$ & $\begin{array}{c}-1.506 * * * \\
(0.400)\end{array}$ & $\begin{array}{c}3.684 * * * \\
(1.295)\end{array}$ & $\begin{array}{l}-21.56 \\
(81.29)\end{array}$ & $\begin{array}{c}5.774 * * * \\
(1.177)\end{array}$ & $\begin{array}{l}-21.44 \\
(66.77)\end{array}$ & \\
\hline $\begin{array}{r}\text { Corrected 80\% } \\
\text { confidence interval }\end{array}$ & & $\begin{array}{l}-2.14 \text { to } \\
-0.92\end{array}$ & & unbounded & & unbounded & \\
\hline Log life expectancy 1940 & & & $\begin{array}{l}3.769 * * * \\
(0.940)\end{array}$ & $\begin{array}{l}-15.23 \\
(61.37)\end{array}$ & $\begin{array}{l}6.848 * * * \\
(0.996)\end{array}$ & $\begin{array}{l}-15.18 \\
(54.28)\end{array}$ & $\begin{array}{l}1.937 * * * \\
(0.552)\end{array}$ \\
\hline Log GDP per capita 1940 & & & & & $\begin{array}{c}-0.689 * * * \\
(0.113)\end{array}$ & $\begin{array}{l}0.0146 \\
(1.810)\end{array}$ & $\begin{array}{c}-0.545^{* * *} \\
(0.142)\end{array}$ \\
\hline Predicted mortality 1940 & & & & & & & $\begin{array}{l}-0.315 \\
(0.442)\end{array}$ \\
\hline Constant & $\begin{array}{l}1.707 * * * \\
(0.163)\end{array}$ & $\begin{array}{c}1.861 * * * \\
(0.189)\end{array}$ & $\begin{array}{c}-14.89 * * * \\
(4.166)\end{array}$ & $\begin{array}{c}69.19 \\
(271.4)\end{array}$ & $\begin{array}{c}-22.34 * * * \\
(3.889)\end{array}$ & $\begin{array}{c}68.81 \\
(224.3)\end{array}$ & $\begin{array}{l}-1.894 \\
(1.933)\end{array}$ \\
\hline Observations & 47 & 47 & 47 & 47 & 47 & 47 & 47 \\
\hline R-squared & 0.194 & 0.174 & 0.325 & -3.127 & 0.603 & -3.095 & 0.448 \\
\hline Cragg-Donald F-Statistic & & 60.84 & & 0.136 & & 0.211 & \\
\hline Critical value for F-Statistics & & 16.38 & & 16.38 & & 16.38 & \\
\hline
\end{tabular}

NOTE.-Robust standard errors in parentheses. $* * * \mathrm{p}<0.01, * * \mathrm{p}<0.05, * \mathrm{p}<0.1$.

In IV (instrumental variable) estimates the growth in life expectancy is instrumented with predicted mortality change.

Based on the Acemoglu and Johnson sample of 47 countries. 
FIGURE 1: LOG LIFE EXPECTANCY 1940 AND PREDICTED MORTALITY

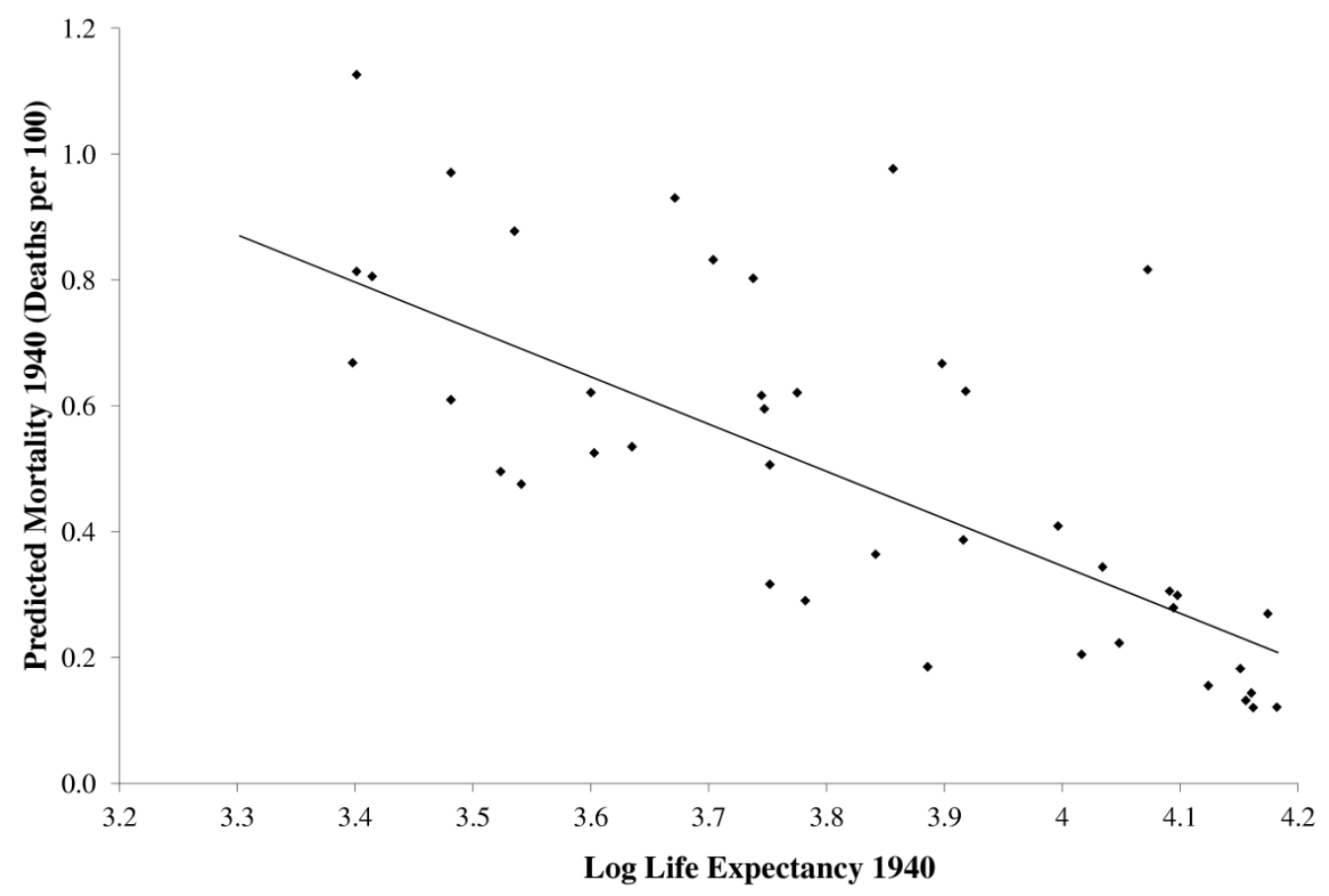

